\title{
Slow formation of a pseudoknot structure is rate limiting in the productive co-transcriptional folding of the self-splicing Candida intron
}

\author{
LIBIN ZHANG, ${ }^{1,2,5}$ PENGHUI BAO, ${ }^{1,2}$ MICHAEL J. LEIBOWITZ, ${ }^{3,4}$ and YI ZHANG ${ }^{1,2}$ \\ ${ }^{1}$ State Key Laboratory of Virology, College of Life Sciences, Wuhan University, Wuhan, Hubei 430072, People's Republic of China \\ ${ }^{2}$ Department of Biochemistry and Molecular Biology, Wuhan University, Wuhan, Hubei 430072, People's Republic of China \\ ${ }^{3}$ Department of Molecular Genetics, Microbiology and Immunology, University of Medicine and Dentistry of New Jersey-Robert Wood Johnson \\ Medical School, Piscataway, New Jersey 08854, USA \\ ${ }^{4}$ Cancer Institute of New Jersey, New Brunswick, New Jersey 08903, USA
}

\begin{abstract}
Pseudoknots play critical roles in packing the active structure of various functional RNAs. The importance of the P3-P7 pseudoknot in refolding of group I intron ribozymes has been recently appreciated, while little is known about the pseudoknot function in co-transcriptional folding. Here we used the Candida group I intron as a model to address the question. We show that co-transcriptional folding of the active self-splicing intron is twice as fast as refolding. The P3-P7 pseudoknot folds slowly during co-transcriptional folding at a rate constant similar to the folding of the active ribozyme, and folding of both P3-P7 and P1-P10 pseudoknots are inhibited by antisense oligonucleotides. We conclude that when RNA folding is coupled with transcription, formation of pseudoknot structures dominates the productive folding pathway and serves as a rate-limiting step in producing the self-splicing competent Candida intron.
\end{abstract}

Keywords: antisense oligonucleotide (AON); Candida albicans; pseudoknot; ribozyme

\section{INTRODUCTION}

As an important class of RNA motifs, a pseudoknot is minimally composed of two helical segments connected by single-stranded regions or loops (Staple and Butcher 2005). RNA pseudoknots play diverse biological roles. They promote programmed ribosomal frameshifting in many viruses (Shen and Tinoco 1995; Nixon et al. 2002). Such a frameshifting signal has been found in bacterial, yeast, and even human genes recently, and therefore is used to predict -1 ribosomal frameshift events (Belew et al 2008; Theis et al. 2008). The P3-P7 pseudoknot is essential for assembly of the compact structure of group I intron ribozymes (Adams et al. 2004). By folding into a doublepseudo-knot structure, the small HDV ribozyme selfcleaves to produce the single-genome RNA of hepatitis

\footnotetext{
${ }^{5}$ Present address: Department of Microbiology, Immunology and Pathology, Colorado State University, 1619 Campus Delivery, Fort Collins, CO 80523, USA.

Reprint requests to: Yi Zhang, State Key Laboratory of Virology, College of Life Sciences, Wuhan University, Wuhan, Hubei 430072, People's Republic of China; e-mail: yizhang@whu.edu.cn; fax: 86-27-68754945.

Article published online ahead of print. Article and publication date are at http://www.rnajournal.org/cgi/doi/10.1261/rna.1638609.
}

delta virus (Thill et al. 1993; Ferré-D’Amaré et al. 1998). It has been reported that there is a highly conserved pseudoknot structure at the $5^{\prime}$ end of the 451-nucleotide (nt) human telomerase RNA, and this pseudoknot is required for telomerase activity (Theimer et al. 2005).

The importance of the P3-P7 pseudoknot in refolding of the Tetrahymena group I ribozyme has been appreciated for over two decades (Laggerbauer et al. 1994; Zarrinkar and Williamson 1994). It has long been recognized that formation of the P3-P7 structure is a rate-limiting step in refolding of the active ribozyme, and the slow kinetics can be converted by mutations destabilizing the alternative P3 base pairing or base triples, or by disconnecting the nonnative interactions (Pan and Woodson; 1998; Rook et al. 1998; Treiber et al. 1998; Ohki et al. 2001; HeilmanMiller and Woodson 2003a). Also, it has been reported that the refolding of the genomic HDV ribozyme is dominated by slow formation of the pseudoknot (Chadalavada et al. 2002).

However, single molecule study has shown that the majority of Tetrahymena group I ribozyme molecules enter the nonproductive folding pathway (Zhuang et al. 2000), raising questions regarding the relevance of the slow $\mathrm{P} 3-\mathrm{P} 7$ 
formation in the productive refolding pathway. Interestingly, we have recently showed that folding of the P3-P7 pseudoknot of the Candida ribozyme in the productive refolding pathway is much more rapid and not rate limiting (Zhang et al. 2005).

Folding kinetics of the pseudoknot during transcription remains unclear. In living cells, RNA folding is coupled with the transcription process (referred to as "co-transcriptional folding"), i.e., each RNA chain starts to fold once it emerges from the polymerase, which is markedly different from "refolding" starting from a full-length RNA molecule. Interestingly, coupling of folding with in vitro transcription accelerates the native folding of the Tetrahymena ribozyme and an RNase P ribozyme about onefold (Pan et al. 1999; Heilman-Miller and Woodson 2003b).

The P3-P7 pseudoknot is a conserved core structure among all group I ribozymes (Michel and Westhof 1990). Absence of this structure results in inactive ribozyme, and thus ribozyme activity provides a direct readout for the correct formation of the pseudoknot. Here we used the Candida group I intron as a model to study the folding kinetics of the P3-P7 pseudoknot during transcription. Interestingly, we demonstrated that both $\mathrm{P} 3-\mathrm{P} 7$ and P1P10 pseudoknots are effectively captured by antisense oligonucleotides (AONs), suggesting a slow formation of these two pseudoknots. We further showed that formation of the native P3-P7 pseudoknot serves as a rate-limiting step during co-transcriptional folding of the catalytically active Candida intron, which dramatically differs from its refolding behavior. This finding suggests that the folding kinetics of the pseudoknot structure is reprogrammed by the transcription process.

\section{RESULTS AND DISCUSSION}

\section{Co-transcriptional folding of the self-splicing Candida intron is twice as fast as refolding}

When the purified transacting Candida ribozyme Ca.L-11 that catalyzes the esterification reaction at the $5^{\prime}$ splice site is refolded in the presence of $\mathrm{Mg}^{2+} \geq 2 \mathrm{mM}$, the major ribozyme population reaches its active structure with a rate constant of $2 \mathrm{~min}^{-1}$ via a pathway in which the P3-P7 pseudoknot forms much more rapidly (Xiao et al. 2003; Zhang et al. 2005). Another transacting Candida ribozyme catalyzing the exon ligation at $3^{\prime}$ splice site also shows a fast folding constant $\left(\geq 1.8 \mathrm{~min}^{-1}\right.$ ) (Bao et al. 2008). Interestingly, under the similar refolding condition, $<20 \%$ of the self-splicing intron molecules folded to the catalytically active structure with a rate constant of $0.09 \mathrm{~min}^{-1}$ (Fig. 1A), suggesting that the presence of long exon sequences dramatically decreases both the rate and efficiency in folding of the Candida intron (Woodson and Cech 1991).

We next addressed how the transcription process modulates the folding kinetics of the self-splicing Candida

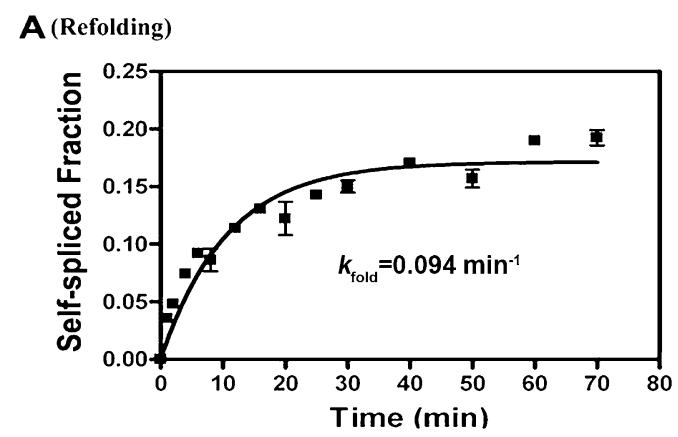

B (Co-transcriptional folding)

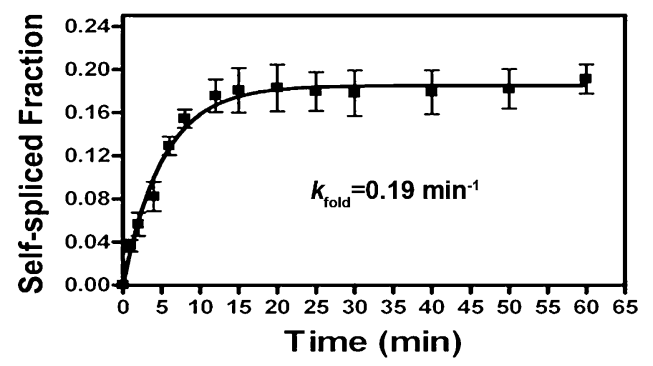

FIGURE 1. The kinetics of refolding and single-round co-transcriptional folding of the self-splicing Candida group I intron. (A) The observational first-order reaction constant for the ribozyme refolding $\left(k_{\mathrm{fold}}=0.094 \pm 0.011 \mathrm{~min}^{-1}\right)$ was determined by plotting the fraction of spliced ribozyme against the splicing time, and then calculated by fitting curves to a single exponential equation. The precursor RNA was purified and denatured as previously described (Zhang et al. 2005), and refolded and spliced in the same transcription condition as for the co-transcriptional folding in the presence of $10 \mathrm{mg} / \mathrm{mL}$ heparin (Materials and Methods). (B) Similarly, the observational first-order reaction constant for folding of the self-splicing ribozyme during oneround transcription $\left(k_{\text {fold }}=0.19 \pm 0.02 \mathrm{~min}^{-1}\right)$ was obtained. Folding of the active structure of the Candida group I intron is much slower than catalysis of each ester-transfer reaction (Jiang et al. 2006; Bao et al. 2008); thus, the observed self-splicing activity in this study reflects the folding kinetics of the ribozyme.

intron. Heparin was used to study the single-round cotranscriptional folding kinetics (Heilman-Miller and Woodson 2003b); and $10 \mathrm{mg} / \mathrm{mL}$ heparin ensured a fast single-round transcription from each template (data not shown). As shown in Figure 1B, a folding rate of 0.19 $\min ^{-1}$ was obtained, demonstrating that co-transcriptional folding of the self-splicing Candida ribozyme is about twice as fast as refolding. This increase is similar to those observed for the Tetrahymena group I ribozyme (HeilmanMiller and Woodson 2003b) and the RNase P ribozyme (Pan et al. 1999).

\section{Co-transcriptional folding, but not refolding of both pseudoknots, of the self-splicing Candida intron is sensitive to AON inhibition}

We have recently showed that co-transcriptional formation of the P3-P7 pseudoknot of the Candida intron is inhibited 
by AONs, suggesting this pseudoknot forms slowly when folding is coupled with transcription (Zhang et al. 2009). The folding kinetics of all different local structures of intron was measured by using 21 AONs covering the whole intron; these AONs were designed to pair with the corresponding target sequence with similar affinity (Fig. 2B). Each $\mathrm{AON}$ at $4 \mu \mathrm{M}$ was added to either the co-transcriptional folding condition or the refolding condition where the precursor RNA was incubated with transcription buffer and T7 polymerase. Only the slow folding regions should be accessible to the complementary AONs.

Interestingly, none of these AONs significantly inhibits refolding of the active self-splicing ribozyme (Figs. 2C,E), suggesting a faster ribozyme refolding than the $\mathrm{AON}$ binding. This is consistent with the fast refolding of the active trans-acting Candida ribozymes (Xiao et al. 2003;
Bao et al. 2008). Strikingly, the co-transcriptional ribozyme folding was dramatically slowed by AONs targeting two pseudoknot structures, including AONs 239-260R, 239$262 \mathrm{R}, 242-260 \mathrm{R}$, and $242-262 \mathrm{R}$ that target the P3-P7 pseudoknot, as well as AON 1-26R targeting the P1-P10 pseudoknot (Fig. 2). Both pseudoknot structures are known to be essential for the self-splicing activity: P3-P7 pseudoknot constitutes the catalytic active site of the ribozyme, while P1-P10 pseudoknot contains both the 5' and $3^{\prime}$ splice sites ( $\mathrm{Li}$ and Zhang. 2005). These results suggested that the transcription process reprograms the folding of these pseudoknots to kinetics slow enough to be bound and interrupted by pseudoknot-targeted AONs.

Ribonuclease $\mathrm{H}$ experiments showed that all AONs precisely bound to the predicted sites and produced the corresponding cleaved RNA segments (Supplemental Fig.
A

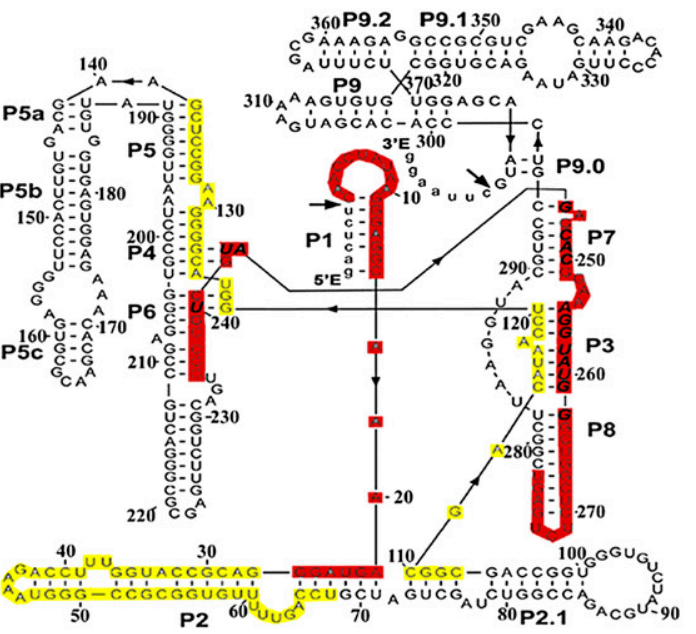

B

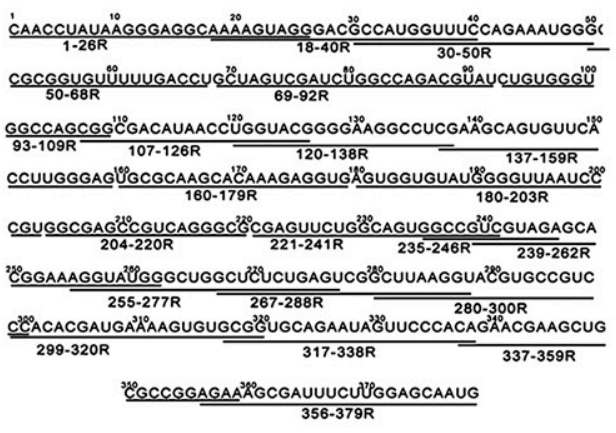

C

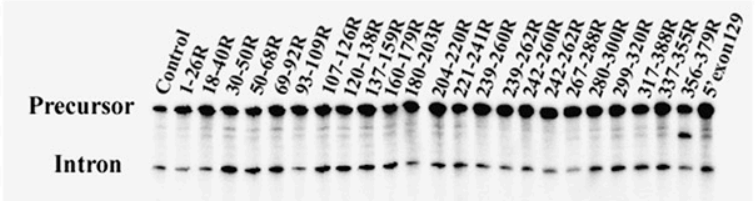

Ligated exon

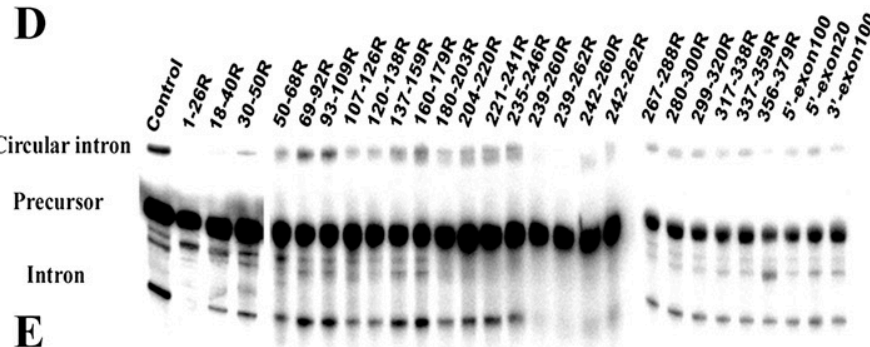

$\mathbf{E}$

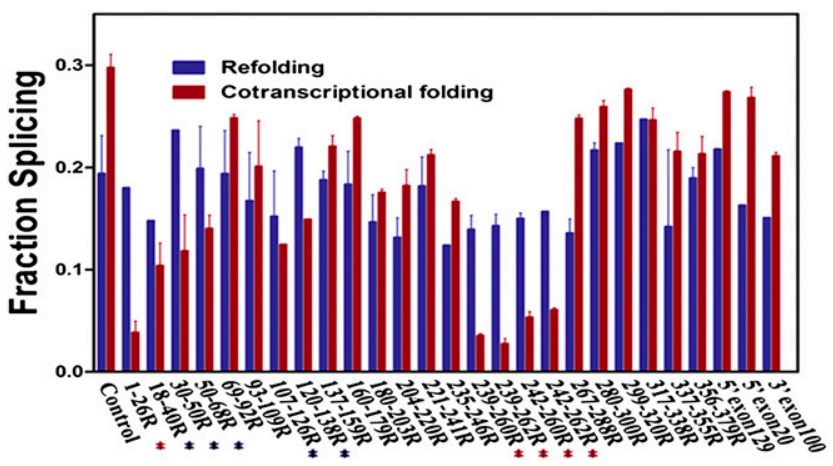

FIGURE 2. Identification of the functionally important substructures of the Candida group I intron whose formation is interrupted by AONs. (A) The secondary structure of the intron including two short exons. The two arrows indicate the $5^{\prime}$ and $3^{\prime}$ sites of the self-splicing intron. The regions most responsive to AON inhibition during co-transcriptional folding are shaded in red, and the moderately responsive regions are in yellow. The bold italic nucleotides have the most significant contributions to the AON inhibition. (B) The primary sequence of the Candida group I ribozyme, with the complementary region of the 21 AONs being underlined. For the name of each AON, the numbers indicate the ribozyme region with which it base pairs, and " $\mathrm{R}$ " stands for the antisense sequence. $(C)$ self-splicing assay of the refolding of the intron substructures. The purified precursor rRNA was refolded in the absence (control) or presence of $4 \mu \mathrm{M}$ of each indicated AON for $1 \mathrm{~h}$. (D) Co-transcriptional self-splicing assay. The precursor rRNA was transcribed in vitro in the absence (control) or presence of $4 \mu \mathrm{M}$ of each indicated AON for $1 \mathrm{~h}$. (E) Quantitative analysis and plotting of the results in $C$ and $D$. Fraction of self-splicing indicates the ratio of the spliced precursor RNA to the total precursor RNA. Red asterisks indicate AONs strongly inhibit the co-transcriptional ribozyme folding, while the blue ones indicate those showing moderate inhibition. 
S1), validating the hypothesis that AON-directed inhibition of intron splicing is due to the specific AON binding.

\section{P3-P7 pseudoknot formation becomes rate limiting during the co-transcriptional folding of the self-splicing Candida ribozyme}

An RNase H-cleavage experiment was then conducted to monitor the P3-P7 folding rate in the whole ribozyme precursor population (Zarrinkar and Williamson 1994). As shown in Figure 3A, a folding rate of about $0.04 \mathrm{~min}^{-1}$ was obtained for one-round transcription. A similar folding rate constant $0.07 \mathrm{~min}^{-1}$ was obtained for multiple-round transcribed precursor RNA (Fig. 3B). This rate is obviously slower than the co-transcriptional folding of the active ribozyme (Fig. 1B), and may reflect what occurs in a nonproductive folding pathway in which RNA molecules are trapped in misfolded structures.

The rate of co-transcriptional folding of the P3-P7 pseudoknot in the productive folding pathway was then measured based on the fact that disruption of the native pseudoknot formation by AONs compromises the ribozyme activity. We folded single-round transcribed selfsplicing Candida ribozyme for the indicated time, then added 240-261R (final concentration $10 \mu \mathrm{M}$ ) to each folding reaction and kept the total folding time (including prior to and after the addition of $240-261 \mathrm{R}$ oligonucleotide) as $1 \mathrm{~h}$. Figure $3 \mathrm{C}$ demonstrates that the productive $\mathrm{P} 3-\mathrm{P} 7$ pseudoknot folded at a rate constant of $0.2 \mathrm{~min}^{-1}$, which is similar to the rate of folding the active self-splicing ribozyme (see Figure 1B). Therefore, formation of the native P3-P7 pseudoknot dominates the native co-transcriptional folding pathway and serves as the rate-limiting step in the folding of the self-splicing Candida ribozyme.

\section{The transcription process may reprogram the folding pathway of group I introns by altering the folding kinetics of pseudoknots}

The slow folding nature of the P3-P7 pseudoknot structure when the purified Tetrahymena group I ribozyme RNA is subjected to refolding has been appreciated since 1994 (Zarrinkar and Williamson 1994); but a single molecule study (Zhuang et al. 2000) suggests that slow P3-P7 formation is a hallmark of the nonproductive folding pathway. Consistently, our study of the Candida group I ribozyme shows that refolding of the $\mathrm{P} 3-\mathrm{P} 7$ pseudoknot in the productive folding pathway is fast and not rate limiting, and the failure of rapid P3-P7 formation leads the ribozyme to a nonproductive folding pathway (Xiao et al. 2003; Zhang et al. 2005; this study). A study from the Woodson group also shows that refolding of the P3-P7 of the Azoarcus ribozyme is much more rapid than folding of the catalytically active ribozyme (Rangan et al. 2003). Therefore, there is no previous strong evidence to show that $\mathrm{P} 3-\mathrm{P} 7$ formation is rate limiting in the productive refolding of group I introns.

This report clearly demonstrates that formation of both P3-P7 and P1-P10 pseudoknots of the Candida group I intron is significantly slowed down during co-transcriptional folding. Formation of P3-P7 pseudoknot becomes rate

A
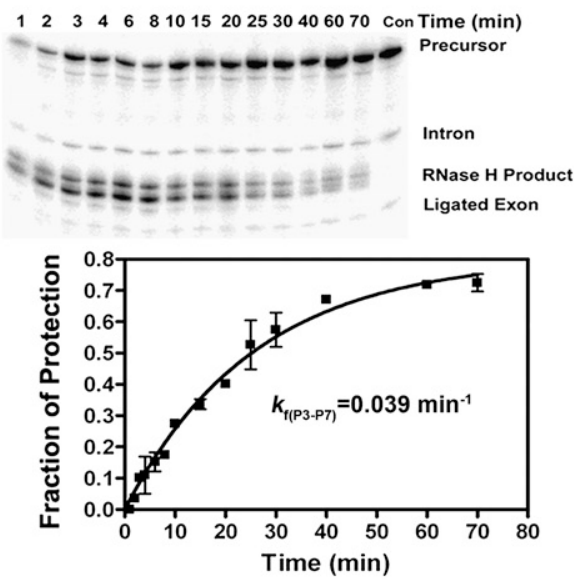

B

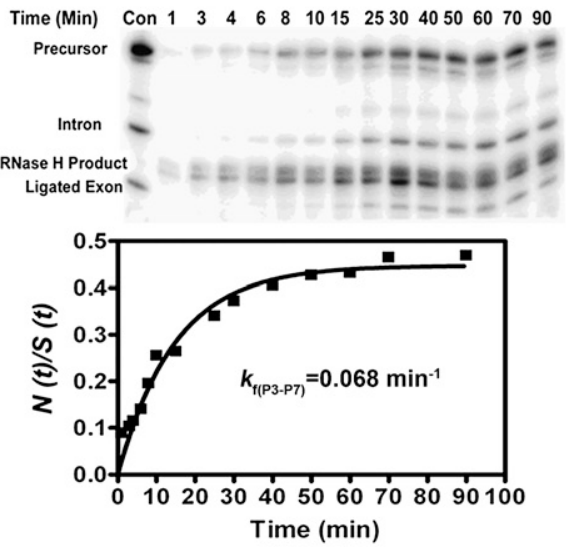

C
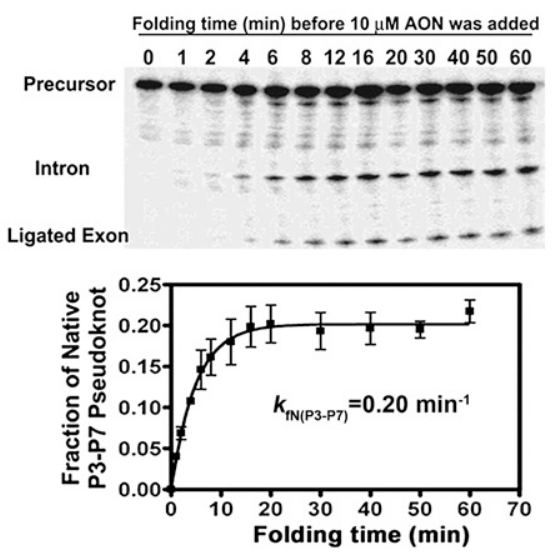

FIGURE 3. (Legend on next page) 
limiting in co-transcriptional folding of the catalytically active ribozyme. This may not be surprising when we consider that during in vitro transcription, after the first strand of the P3 helix emerges from the RNA polymerase, it has to wait nearly $1 \mathrm{sec}$ for the second strand to be released. During this time delay, the naked first strand has many opportunities to form alternative stable structures with RNA sequences synthesized prior to the correct complementary strand (Fig. 4). Because of the high thermodynamic stability and slow dissociation kinetics of these mispaired structures (Uhlenbeck. 1995), formation of the correct P3-P7 pseudoknot is thus delayed. Consistent with this concept, this study suggests that another long-range base-pairing structure $\mathrm{P} 4-\mathrm{P} 5$ also forms slowly during cotranscriptional folding (Figs. 2C, E). Thus, despite cotranscriptional folding being faster than refolding, its ratelimiting pseudoknot folding step in the pathway to the active ribozymes is slower and rate limiting.

This report suggests that the transcription process may reprogram the folding pathway of group I introns and other structured RNAs by altering the folding kinetics of long-range base paired structures. In this regard, it is likely that a critical pseudoknot in a highly structured RNA could act as a sensor of the transcription rate to regulate the folding of the active structure of the host RNA, and therefore could couple the functional RNA folding with the cell growth condition.

\section{Implications for RNA-targeted chemotherapy}

Functional RNAs represent new therapeutic targets, and extensive studies have been carried out to develop anti-RNA therapeutic approaches. It has previously been demonstrated that inhibitors of group I introns that alter the ribozyme folding can act as antimicrobial agents in Candida strains in which the function of such ribozymes is essential

FIGURE 3. Measuring the kinetics of co-transcriptional folding of the P3-P7 pseudoknot using AON 240-261R. (A) Detection of the formation of the P3-P7 pseudoknot structure by RNase $\mathrm{H}$ cleavage during single-round transcription. A representative gel is shown in the upper panel, and the results of two independent experiments were quantified. The fraction of the intact RNA was plotted against the transcription time by fitting curves to a single exponential, resulting in an observed folding constant $\left(k_{\mathrm{f}(\mathrm{P} 3-\mathrm{P} 7)}\right)$ of $0.039 \pm 0.003 \mathrm{~min}^{-1}$ (lower panel). (B) Detection of the formation of the P3-P7 pseudoknot structure by RNase $\mathrm{H}$ cleavage during multiple-round transcription. $S(t)$ indicated the amount of total precursor synthesized at each time point and $N(t)$ indicated the amount of the ribozyme with the folded P3-P7 pseudoknot (inaccessible to RNase $\mathrm{H}$ ) at each time point. The folding rate of the P3-P7 pseudoknot in the nascent RNA transcript was described as $N(t) / S(t)=1-\left(1-\mathrm{e}^{-k \mathrm{f} \cdot \mathrm{t}}\right) / k_{\mathrm{f}} \mathrm{t}$ (Pan et al. 1999), resulting in a $k_{\mathrm{f}(\mathrm{P} 3-\mathrm{P} 7)}$ of $0.068 \pm 0.006 \mathrm{~min}^{-1}$. (C) Detection of the formation of the native P3-P7 pseudoknot during single-round transcription. Self-splicing was conducted for $1 \mathrm{~h}$ for each reaction and the AON 240-261R was added at each indicated time during the reaction. The splicing fraction was plotted as in Figure 1, resulting in an $k_{\mathrm{fN}(\mathrm{P} 3-\mathrm{P} 7)}$ of $0.20 \pm 0.02 \mathrm{~min}^{-1}$. for viability (Miletti and Leibowitz 2000; Zhang et al. 2002). This report shows that the splicing activity of the C. albicans group I ribozyme is effectively compromised by AONs interrupting the folding of functionally important pseudoknot structures. We have recently shown that AONs targeting the P3-P7 pseudoknot specifically and effectively kill the intron-containing C. albicans strains (Zhang et al. 2009). Therefore, oligonucleotides blocking the co-transcriptional formation of the pseudoknot structure of the target RNA represent a new class of potential therapeutic agents.

\section{MATERIALS AND METHODS}

The template DNA for in vitro transcription of the precursor RNA (658 nt) contained the Candida intron, as well as $70 \mathrm{nt}$ upstream and $209 \mathrm{nt}$ downstream adjacent host rRNA sequence (Zhang et al. 2009). All of the in vitro reactions were analyzed on 5\% polyacrylamide-8 $\mathrm{M}$ urea gels that were then exposed onto PhosphorImager screens for visualization and quantitative analysis using the variable scanner Typhoon 9200 (Amersham Pharmacia Biotech). The data were then plotted using the GraphPad Prism 4.0 program (www.graphpad.com).

\section{Assay of the in vitro folding of the self-splicing Candida ribozyme}

To study the ribozyme folding during multiple-round transcription, the template DNA was transcribed and spliced in $10 \mu \mathrm{L}$ reactions containing six units of T7 polymerase, $500 \mu \mathrm{M}$ of rATP, rCTP, and rUTP, $100 \mu \mathrm{M}$ rGTP, and $0.01 \mu \mathrm{Ci}\left[\alpha-{ }^{32} \mathrm{P}\right] \mathrm{GTP}$ $\left(3000 \mathrm{Ci} / \mathrm{mmol}\right.$ ) in $10 \mu \mathrm{L}$ of $1 \times \mathrm{T} 7$ transcription buffer at $37^{\circ} \mathrm{C}$ for $60 \mathrm{~min}$, in the presence or absence of AONs. Because $6 \mathrm{mM}$ of $\mathrm{Mg}^{2+}$ and sufficient GTP were present, the ribozyme self-splicing occurred during transcription. The reactions were stopped by EDTA-containing loading buffer, and analyzed on denature PAGE gels. To study the active ribozyme refolding, the purified Candida intron precursor was incubated at the same condition as for the co-transcriptional folding.

To study the ribozyme folding during single-round transcription, $1 \mu \mathrm{g}$ of the same template DNA was mixed with $20 \mu \mathrm{Ci}$ $\left[\alpha-{ }^{32} \mathrm{P}\right]$ GTP $(3000 \mathrm{Ci} / \mathrm{mmol})$ (Perkin-Elmer-NEN) and 200 units T7 RNA polymerase (MBI Fermentas) in T7 transcription buffer. This mixture was incubated for $2 \mathrm{~min}$ at $37^{\circ} \mathrm{C}$. Then a mixture of four nucleotides (Roche) and heparin (Sigma) was added to bring the reaction volume to $40 \mu \mathrm{L}$ and final concentrations of rATP, rCTP, and rUTP to $0.5 \mathrm{mM}$, rGTP to $0.125 \mathrm{mM}$, and heparin to $10 \mathrm{mg} / \mathrm{mL}$. To measure the rate constant for folding of the active self-splicing Candida ribozyme, a $2 \mu \mathrm{L}$ aliquot was removed immediately after the addition of four nucleotides and heparin for the zero time point, which was actually about a 5-10-sec reaction due to the time required for the manual operation. At various time points, $2 \mu \mathrm{L}$ aliquots were removed and mixed with loading dyes containing EDTA.

To measure the rate constant for folding of the native P3-P7 pseudoknot, the $2 \mu \mathrm{L}$ aliquots were removed at various time points and placed into an $8 \mu \mathrm{L}$ reaction mix containing $1 \times \mathrm{T} 7$ buffer (final concentration) and unmodified 240-261R oligonucleotide (AON, final concentration of $10 \mu \mathrm{M}$ ). The mixture continued to react at $37^{\circ} \mathrm{C}$ and the total reaction time including 


\section{Transcription-coupled folding in vitro:}

\section{Rate-limiting formation of P3-P7 pseudoknot and other long-range base-pairing}
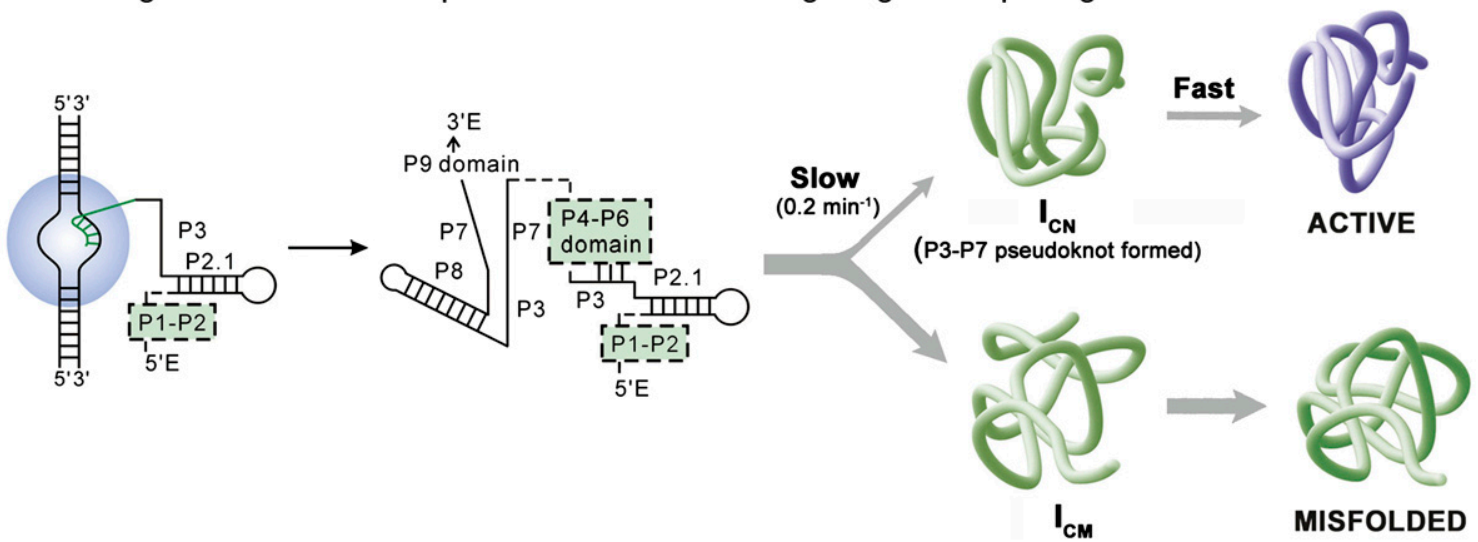

FIGURE 4. A model of the group I intron RNA folding scheme during in vitro transcription (see the text for details).

prior to and after the addition of T7 buffer and 240-261R oligonucleotide was kept as $1 \mathrm{~h}$ for each reaction.

To measure the mixed folding rate of the P3-P7 structure, the $2 \mu \mathrm{L}$ aliquots removed at each time point were immediately subjected to a 0.5-min RNase H cleavage assay (Zarrinkar and Williamson 1994). The reaction concentrations of AONs (SaiBaiSheng) and RNase $\mathrm{H}$ (Takara) were $10 \mu \mathrm{M}$ and $0.4 \mathrm{U} / \mu \mathrm{L}$, respectively.

\section{SUPPLEMENTAL MATERIAL}

Supplemental material can be found at http://www.rnajournal.org.

\section{ACKNOWLEDGMENTS}

We thank our colleagues in Dr. Yi Zhang's laboratory, and Ms. Lili Guo for generating the artwork. This work is supported by the National Natural Science Foundation of China (90608025 and 30770422) and by the National Basic Research Program of China (2005CB724604) through grants awarded to Y.Z.

Received March 8, 2009; accepted July 30, 2009.

\section{REFERENCES}

Adams PL, Stahley R, Gill ML, Kosek AB, Wang J, Strobel SA. 2004. Crystal structure of a group I intron splicing intermediate. RNA 10: $1867-1887$.

Bao P, Wu QJ, Yin P, Jiang Y, Wang X, Xie M-H, Sun T, Huang L, Mo D-D, Zhang Y. 2008. Coordination of two sequential estertransfer reactions: Exogenous guanosine binding promotes the subsequent $\omega \mathrm{G}$ binding to a group I intron. Nucleic Acids Res 36: 6934-6943.

Belew AT, Hepler NL, Jacobs JL, Dinman JD. 2008. PRFdb: A database of computationally predicted eukaryotic programmed -1 ribosomal frameshift signals. BMC Genomics 9: 339. doi: 10.1186/14712164-0-339.

Chadalavada DM, Sencha SE, Bevilacqua PC. 2002. The folding pathway of the genomic hepatitis delta virus ribozyme is dominated by slow folding of the pseudoknots. J Mol Biol 317: 559-575.

Ferré-D’Amaré AR, Zhou K, Doudna JA. 1998. Crystal structure of a hepatitis delta virus ribozyme. Nature 395: 567-574.
Heilman-Miller SL, Woodson SA. 2003a. Perturbed folding kinetics of circularly permuted RNAs with altered topology. J Mol Biol 328: 385-394.

Heilman-Miller SL, Woodson SA. 2003b. Effect of transcription on folding of the Tetrahymena ribozyme. RNA 9: 722-733.

Jiang YF, Xiao M, Yin P, Zhang Y. 2006. Monovalent cations use multiple mechanisms to resolve ribozyme misfolding. RNA 12: 561-566.

Laggerbauer B, Murphy FL, Cech TR. 1994. Two major tertiary folding transitions of the Tetrahymena catalytic RNA. EMBO J 13: 2669-2676.

Li Z, Zhang Y. 2005. Predicting the secondary structures and tertiary interactions of 211 group I introns in IE subgroup. Nucleic Acids Res 33: 2118-2128.

Michel F, Westhof E. 1990. Modeling of the three-dimensional architecture of group I catalytic introns based on comparative sequence analysis. J Mol Biol 216: 585-610.

Miletti KE, Leibowitz MJ. 2000. Pentamidine inhibition of group I intron splicing in Candida albicans correlates with growth inhibition. Antimicrob Agents Chemother 44: 958-966.

Nixon PL, Rangan A, Kim YG, Rich A, Hoffman DW, Hennig M, Giedroc DP. 2002. Solution structure of a luteoviral P1-P2 frameshifting mRNA pseudoknot. J Mol Biol 322: 621-633.

Ohki Y, Ikawa Y, Shiraishi H, Inoue T. 2001. A deteriorated triplehelical scaffold accelerates formation of the Tetrahymena ribozyme active structure. FEBS Lett 493: 95-100.

Pan J, Woodson SA. 1998. Folding intermediates of a self-splicing RNA: mispairing of the catalytic core. J Mol Biol 280: 597-609.

Pan T, Artsimovitch I, Fang XW, Landick R, Sosnick TR. 1999. Folding of a large ribozyme during transcription and the effect of the elongation factor NusA. Proc Natl Acad Sci 96: 9545-9550.

Rangan P, Masquida B, Westhof E, Woodson SA. 2003. Assembly of core helices and rapid tertiary folding of a small bacterial group I ribozyme. Proc Natl Acad Sci 100: 1574-1579.

Rook MS, Treiber DK, Williamson JR. 1998. Fast folding mutants of the Tetrahymena group I ribozyme reveal a rugged folding energy landscape. J Mol Biol 281: 609-620.

Shen LX, Tinoco I Jr. 1995. The structure of an RNA pseudoknot that causes efficient frameshifting in mouse mammary tumor virus. $J$ Mol Biol 247: 963-978.

Staple DW, Butcher SE. 2005. Pseudoknots: RNA structures with diverse functions. PLoS Biology 3: 0956-0959.

Theimer CA, Blois CA, Feigon J. 2005. Structure of the human telomerase RNA pseudoknot reveals conserved tertiary interactions essential for function. Mol Cell 17: 671-682. 


\section{Zhang et al.}

Theis C, Reeder J, Giegerich R. 2008. KnotInFrame: Prediction of -1 ribosomal frameshift events. Nucleic Acids Res 36: 6013-6020.

Thill G, Vasseur M, Tanner NK. 1993. Structural and sequence elements required for the self-cleaving activity of the hepatitis delta virus ribozyme. Biochemistry 32: 4254-4262.

Treiber DK, Rook MS, Zarrinkar PP, Williamson JR. 1998. Kinetic intermediates trapped by native interactions in RNA folding. Science 279: 1943-1946.

Uhlenbeck OC. 1995. Keeping RNA happy. RNA 1: 4-6.

Woodson SA, Cech TR. 1991. Alternative secondary structures in the $5^{\prime}$ exon affect both forward and reverse self-splicing of the Tetrahymena intervening sequence RNA. Biochemistry 30: 2042-2050.

Xiao M, Leibowitz MJ, Zhang Y. 2003. Concerted folding of a Candida ribozyme into the catalytically active structure posterior to a rapid RNA compaction. Nucleic Acids Res 31: 3901-3908.
Zarrinkar PP, Williamson JR. 1994. Kinetic intermediates in RNA folding. Science 265: 918-924.

Zhang Y, Li Z, Pilch DS, Leibowitz MJ. 2002. Pentamidine inhibits catalytic activity of group I intron Ca.LSU by altering RNA folding. Nucleic Acids Res 30: 2961-2971.

Zhang L, Xiao M, Lu C, Zhang Y. 2005. Fast formation of the P3-P7 pseudoknot: A strategy for efficient folding of the catalytically active ribozyme. RNA 11: 59-69.

Zhang L, Leibowitz MJ, Zhang Y. 2009. Antisense oligonucleotides effectively inhibit the co-transcriptional splicing of a Candida group I intron in vitro and in vivo: Implications for antifungal therapeutics. FEBS Lett 583: 734-738.

Zhuang XW, Bartley LE, Babcock HP, Russell R, Ha T, Herschlag D, Chu S. 2000. A single-molecule study of RNA catalysis and folding. Science 288: 2048-2051. 

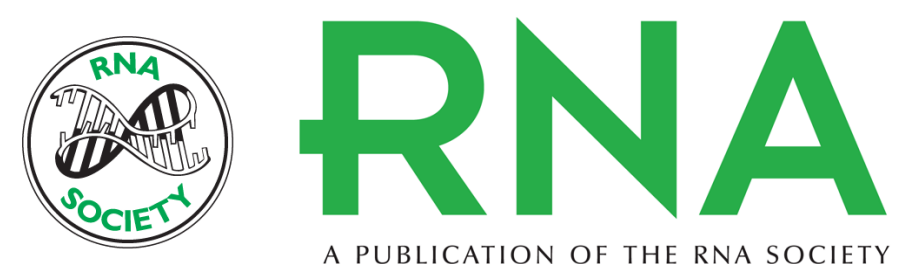

A PUBLICATION OF THE RNA SOCIETY

\section{Slow formation of a pseudoknot structure is rate limiting in the productive co-transcriptional folding of the self-splicing Candida intron}

Libin Zhang, Penghui Bao, Michael J. Leibowitz, et al.

RNA 2009 15: 1986-1992 originally published online August 26, 2009

Access the most recent version at doi:10.1261/rna.1638609

Supplemental http://rnajournal.cshlp.org/content/suppl/2009/08/26/rna.1638609.DC1

Material

References This article cites 32 articles, 10 of which can be accessed free at:

http://rnajournal.cshlp.org/content/15/11/1986.full.html\#ref-list-1

License

Email Alerting Receive free email alerts when new articles cite this article - sign up in the box at the Service top right corner of the article or click here.

To subscribe to $R N A$ go to:

http://rnajournal.cshlp.org/subscriptions 